\title{
El arte de la traducción en el Humanismo renacentista español
}

\section{(The Art of Translation in the Spanish Humanist Renaissance)}

\author{
JUAN LUIS MONREAL PÉREZ
} Universidad de Murcia

Fecha de recepción: 10 de enero de 2011

Fecha de aceptación: 14 de marzo de 2011

Resumen: El artículo presenta la visión y perspectiva que sobre la traducción tenía la llamada corriente Humanismo renacentista español, bien representada, entre otros, por Nebrija, Juan Luis Vives, Juan de Valdés y Fray Luis de León, principalmente, así como por Bernardo Pérez de Chinchón y Alonso Ruiz de Virués, por su significativa obra en este campo. La obra traductora de todos ellos tiene en común el haber entendido que el oficio de la traducción no conlleva un servilismo literal sino que requiere una tarea de interpretación del texto a verter. El interés adicional que encontramos al examinar las contribuciones que al arte de la traducción tuvieron lugar en este periodo es ver cómo éstas ayudaron a desarrollar en el tiempo la lengua castellana a través de las diversas obras que fueron objeto de traducción por parte de los humanistas españoles.

Palabras clave: Traducción. Interpretación textual. Traducción literal. Traducción libre.

Abstract: The article shows the vision and perspective on translation offered by the currently known as the Spanish Humanist Renaissance, well-represented, among others, by Nebrija, Juan Luis Vives, Juan de Valdés and Fray Luis de León, in the main, as well as Bernardo Pérez de Chinchón and Alonso Ruiz de Virués, for their important work in this field. The translation work of all these authors shares an understanding that the craft of translation does not imply a literal servility to the text, but rather calls for an interpretative task of the work in question. Exploration of the contributions of the art of translation at this time provides added interest in the realisation of how the Castillian language was simultaneously developed via the range of works that were translated by the Spanish humanists.

Key words: Translation. Text Interpretation. Literal Translation. Free Translation.

\section{INTRODUCCIÓN}

En este texto se examina el modo de entender el arte de la traducción por parte de lo que podemos denominar el Humanismo Renacentista Español. Esta corriente humanista hay que considerarla como reformadora en el modo de entender y representarse el mundo y en la forma de interpretar el papel de las letras. 
El interés que tiene, desde nuestra perspectiva, analizar el modo de entender el arte de la traducción, radica en que ha contribuido también a desarrollar en el tiempo la lengua castellana a través de las diversas aportaciones que tuvieron lugar. Éstas se han formado y expandido no de forma espontánea, sino gracias al uso continuado de la lengua que se produjo y al esfuerzo de traducir de una lengua a otra llevado a cabo por notables humanistas españoles. Obviamente, ni nos es posible ni ha lugar hacer una revisión de todas las aportaciones significativas que en España se han hecho desde el punto de vista de cómo entender el arte de la traducción. Precisamente por ello, nos limitamos a examinar solo algunos personajes relevantes del periodo y de la corriente humanista renacentista española como Bernardo Pérez de Chinchón y Alonso Ruiz de Virués, Nebrija, Juan Luis Vives, Juan de Valdés y Fray Luis de León. La obra traductora de todos ellos tiene en común el haber entendido que el oficio de la traducción no conlleva un servilismo literal sino que requiere una tarea de interpretación del texto a verter.

\section{Bernatido pérez de Chinchón y Alonso Ruiz de Virués como TRADUCTORES DE LA OBRA DE ERASMO}

La obra de Erasmo (1467-1536) fue amplia y rápidamente traducida a diferentes lenguas vernáculas europeas. La explicación de tal hecho se debió principalmente a dos razones: la primera, por la atracción que produjo el pensamiento de Erasmo, los contenidos que abordó y el lenguaje y estilo que utilizó. La segunda razón, por el hecho de que el latín, lengua en la que el holandés escribió, no era accesible sino a una minoría de aquella amplia población que constituía el mercado potencial de lectores de Erasmo. Esta situación real forzó la rápida traducción de la obra de Erasmo a diferentes lenguas vernáculas dominantes en Europa.

Lógicamente, el trabajo de traducción de la obra de Erasmo del latín a las correspondientes lenguas vernáculas, supuso en cada caso una aportación singular, no solo por los contenidos temáticos que se incorporaban a dicha lengua vernácula, sino también por los elementos lingüísticos, gramaticales, culturales y religiosos que ello significaba.

Erasmo tuvo una fuerte influencia en España y las traducciones de sus trabajos se difundieron también muy tempranamente en los ambientes católicos más sensibles de la Iglesia española. Ello supuso, desde el punto de vista de la lengua castellana, un impulso al desarrollo de la misma, ya que se encontraba todavía en proceso de constitución y maduración.

Bernardo Pérez de Chinchón (1497-1556) y Alonso Ruiz de Virués (1469-1536), hombres cercanos en el tiempo y en las letras acometieron las traducciones de dos obras de Erasmo, Lingua y Coloquios Familiares y las 
llevaron a cabo bajo las siguientes condiciones: buen conocimiento del autor; buen manejo de las lenguas traducir e interpretar; proximidad histórica de la traducción a la publicación de la obra original; e interés por contribuir con la traducción al desarrollo de la lengua vernácula, en este caso el castellano. Creemos que las traducciones hechas bajo estas condiciones, le dan a las mismas un interés y relevancia especial, ya que cumplen algunos requisitos que Gadamer considera necesarios en toda obra de traducción:

El traductor tiene que trasladar aquí el sentido que se trata de comprender al contexto en el que vive el otro interlocutor. Pero esto no quiere decir en modo alguno que le esté permitido falsear el sentido al que se refería el otro. Precisamente lo que tiene que mantener es el sentido, pero como tiene que comprenderse en un mundo lingüístico nuevo, tiene que hacerse valer en él de una forma nueva. Toda traducción es por eso ya una interpretación, e incluso puede decirse que es la consumación de la interpretación que el traductor hace madurar en la palabra que se le ofrece (Gadamer, 2005:462).

\section{1. Traducción de la obra Lingua de Erasmo por Bernardo Pérez de Chinchón $^{1}$}

Para apreciar bien el valor de la obra Lingua y la labor de traducción de Bernardo Pérez de Chinchón es interesante conocer la opinión al respecto del reconocido experto en Erasmo como es Marcel Bataillon, quien no se ha atrevido a identificar a Pérez de Chinchón como el traductor de dicha obra:

El traductor destacó su orden aparente con una división en tres partes. Bienes y males de la lengua se demostraban abundantemente, primero por medio de las anécdotas sacadas de la antigüedad profana, y después por medio de autoridades de la Sagrada Escritura. Una tercera parte mostraba los remedios apropiados a los males de este temible órgano [...] El traductor, quienquiera que fuese, era con seguridad hombre hábil [...] En una breve advertencia al lector, se excusa de haber tomado algunas libertades con el texto. No oculta que ha modificado los pasajes en que Erasmo maltrata a los frailes:

\footnotetext{
${ }^{1}$ Pérez de Chinchón fue un erasmista reconocido y judío converso que, como en el caso de Vives, había visto castigada a su familia castellana. Fue un servidor de Juan de Borja, señor de Gandía. Aprovechando el encuentro de éste con el rey Carlos I en Valencia, y estando presente en el mismo Alonso Manrique, Inquisidor General, Pérez de Chinchón se le acercó a éste con un libro en la mano, el Antialcorano, para obtener el visto bueno para su edición, cosa que logró. Además de este escrito, debía de llevarle al Inquisidor bajo el brazo la traducción de una atrevida obra de Erasmo, los Silenos de Alcibíades, y quién sabe si también la versión de la Lengua, libros que sin duda alegraría los ojillos de Alfonso de Valdés, también en el séquito del emperador (Cf. Villacañas, 2008: 214-215).
} 


\begin{abstract}
bien sabe que esas críticas están inspiradas por el celo y no por la malignidad, que apuntan contra los errores, no contra los hombres ni contra el hábito que éstos llevan; pero él quiere conducir a los frailes a amar a Erasmo por su doctrina, no a odiarlo por sus censuras. En efecto, si se confronta la traducción con el original, se observa que gran número de pullas se han suavizado o incluso han desaparecido por completo. Los nombres de las dos grandes órdenes mendicantes se han suprimido a menudo. [...] Las notas marginales que facilitan la lectura de este ensayo un poco compacto son además, para el traductor, un medio cómodo de subrayar su ortodoxia [...] En verdad, Erasmo se había engañado al alarmarse de que la Lingua pudiera traducirse al español: el traductor no tuvo que hacer gran esfuerzo de adaptación para que este libro gozara en España de popularidad que no tenía en ninguna otra parte, sin que la Inquisición diera la menor señal de inquietud. (Bataillon, 1986:311-313).
\end{abstract}

No cabe duda que la traducción de la obra de Erasmo Lingua que llevó a cabo Bernardo Pérez de Chinchón no pasó inadvertida, ya que éste consiguió darle cierta relevancia a un trabajo que no es de los más significativos de Erasmo, ya que logró darle estructura, lo acomodó al contexto erasmista de España y mostró con él su buen hacer como traductor, tal como ya había puesto de manifiesto anteriormente en la traducción de otras obras.

¿Cuáles son las contribuciones más significativas de Bernardo Pérez de Chinchón en cuanto traductor del ensayo de Erasmo? Tanto en la obra Lingua como en el resto de sus traducciones, el valenciano se sitúa siempre ante los textos que traduce con una actitud de humildad, lo que no quiere decir que practique un servilismo literal; al contrario, sus traducciones reflejan un espíritu de respeto hacia el texto que traduce, pero -por otra parte-, muestra también sus dotes de interpretación. Esta opinión es avalada por Dorothy S. Severin, el editor de dicho ensayo, cuando dice que el tópico favorito de Bernardo Pérez de Chinchón en su condición de traductor, es la de humildad, refiriendo al respecto las siguientes palabras de Erasmo: "Mi lengua muy tosca te pide perdón, / christiano lector, amigo y hermano; / si en lengua materna de mi castellano, / offenda tu oýdo mi rústico son" [Lengua, fol. 1v] (Severin, 1975: XVII).

Dicha actitud de humildad se complementa en Bernardo Pérez de Chinchón con la de fidelidad a los textos originales. El capiscol, como se le llamaba, añade Severin:

[...] en lugar de añadir comentarios suyos susceptibles de controversia, traducía cuidadosamente y a veces disminuía o cortaba algunos de los comentarios más acérbicos de Erasmo, en particular cuando se mencionan a los dominicos o franciscanos. Lejos de ser un 
discípulo atrevido y franco, parece que Bernardo Pérez fue muy cuidadoso, y sensitivo a los censores inquisicionales y a la jerarquía eclesiástica. Sin duda sus traducciones circunspectas, así como la protección de la familia Borja, le salvaron del hado de otros erasmistas (Severin, 1975:XVI).

Bernardo Pérez de Chinchón, además de su labor de traductor del ensayo Lingua, hace también una introducción al mismo donde expone su pensamiento en relación al uso y la finalidad de la lengua. En primer lugar, considera la lengua como el instrumento de la comunicación y el camino del conocimiento:

Donde conjeturo que el ñudo que Dios puso en esta estatua que es el hombre [...] es la lengua; para que con ella, como con un faraute de la razón, uno hable con otro, y le declare sus pensamientos, sus ymaginaciones, y le ponga en camino de razón, de sciencia, de arte, de justicia, de virtud, de conocimiento, assí de sí mesmo como de Dios y de las criaturas. $Y$ de esta manera de enseñar uno a otro salieron como vemos que han salido, la theología, que es sciencia de Dios; la philosophía natural, que es sciencia de naturaleza; la moral, que es doctrina de las costumbres: la metaphýsica, que es sabiduría de las causas separadas; la grammática, que es arte para hablar congruamente en qualquier lenguage; la lógica, que es artificio para discernir la verdad de la falsedad; la rhethórica que es arte para elocuentemente hablar; la arithmética, que es arte de los números; la geometría, que es arte de medida y compás; la música, que es arte de melodía y proporción de vozes; la astrología, que es arte del movimiento de los planetas y cielos; la agricultura, que es arte de las labranças; las leyes, que son regla para regir la república; la medicina y cirugía, que es arte de curar los cuerpos [...] Las quales todas han salido y cada día salen por la comunicación que unos hombres con otros tienen mediante la lengua (Pérez de Chinchón, 1975:6).

Por otra parte, la lengua debe ser también -en opinión de Pérez de Chinchón-, un vínculo de unidad en los aspectos político (gobierno), social (comunicación) y cultural (identidad):

Es tanta la fuerça de la lengua que por ella antiguamente se juntaron los hombres a poblar ciudades y lugares; por ella se pusieron las leyes; por ella se goviernan las repúblicas; por ella se rigen los ejércitos; por ella se escriben las historias; ella sola es el engrudo, la liga, el ñudo que ata, sustenta y govierna a todo el linaje humano. Bien paresce esto ser assí, pues quando el lenguaje era uno, éramos todos un cuerpo; luego que se partieron los lenguajes, quando los hombres soberbiosamente quisieron edificar aquella torre de Babel, luego se despedaçó esta estatua del hombre que hizo nuestro Dédalo Dios, y 
fuese el un pedazo por acá, y el otro por acullá. No se juntava ya parte con parte, porque faltava el engrudo que era la lengua. De manera, muy reverendo señor, que como de ser el lenguaje uno, éramos todos uno, hazíamos una estatua hermosa, concertada y bien compuesta; assí por averse partido el lenguaje, somos ya muchas partes, y no un todo; feos y no hermosos, desconcertados y mal apuestos (Pérez de Chinchón, 1975:7).

Hasta tal punto Pérez de Chinchón ensalza la unidad del lenguaje, que le lleva a no valorar la realidad de las lenguas vernáculas como la situación ideal, aunque sí acepta el hecho de las mismas:

No concierta ya francés con español, ni inglés con los dos; ni alemán con ytaliano, ni ytaliano con griego, ni griego con asiático, ni asiático con africano, ni los de una nación consideran entre si mesmos; porque a donde se diferencia el lenguaje, allí ay diferencia en la condición y en el amor, y de la diferencia nasce la discordia, y de la discordia viene el apartamiento de la unidad [...] De aquí han venido estos vocablos de mío y tuyo, peor y mejor, señor y criado, reyes y súbditos, hidalgos y labradores, nobles y ceviles, ricos y pobres; de que cada uno tira para sí, cada uno habla su lenguaje, no quiriendo concertar con el otro (Pérez de Chinchón, 1975:7).

Pérez de Chinchón, siguiendo la vía que propone Erasmo en su ensayo Lingua, nos ofrece el lenguaje del evangelio de Jesucristo como lenguaje unificador y universal que remedie las disfunciones que producen las diversidades de lenguajes:

Quiso pues Dios poner remedio en tanta discordia; quiso tornar estas partes a su cuerpo; quiso soldarlas con un betún fortísimo; y que bastasse a hazer más rezio lo quebrado que lo sano. $Y$ para esto embiónos un nuevo lenguaje que anduviesse por todos y que le hablassen todos; un lenguaje santo, honesto, justo, piadoso, discreto, sabio, elegante, polido, que hablasse de las cosas altas de Dios, y de las cosas baxas de las criaturas, y que atasse las unas con las otras, y de tal manera estuviesse en la boca que saliesse del coraçon. Lenguaje que basta a rehacer aquel cuerpo tan partido en sesenta y tantos lenguajes, y que todos se entiendan y junten en un spíritu y un amor, en un cuerpo y figura. Este lenguaje es el evangelio de Jesu Christo (Pérez de Chinchón, 1975:7-8).

Finalmente, Pérez de Chinchón acaba la introducción justificando por qué lleva a cabo la traducción del ensayo de Erasmo del latín al castellano: "para que todos los de mi nación pueden bien entender este lenguaje" (Pérez de Chinchón, 1975:9). Al traductor valenciano le importa, como le 
importaba a Erasmo, que el lenguaje cristiano llegara a los hombres, y a tal fin recurrió al castellano como lengua vernácula.

\subsection{Traducción de la obra Coloquios familiares de Erasmo por Alonso Ruiz} de Virués

La traducción de la obra de Erasmo Coloquios familiares realizada por el benedictino Fray Alonso Ruiz de Virués ${ }^{2}$ tuvo lugar en torno a 1529 cuando ya en España se había desatado un clima muy favorable a Erasmo, el llamado movimiento erasmista español, aunque no faltaban los llamados antierasmistas. Lógicamente, la iniciativa de Ruiz de Virués como traductor y editor de los Coloquios responde a su estima por Erasmo, de quien está convencido de la ortodoxia de sus escritos, y por ello no duda en salir en defensa suya ante quienes intentan cuestionarlo, como fue el caso del Guardián de Alcalá, a quien le dirige una carta por las cosas que dijo contra Erasmo. Es tal el valor que Ruiz de Virués da a tal carta, que no duda en incorporarla al Prólogo que hace a los Coloquios bajo el título Argumento y protestación del autor en la carta siguiente, que se pone en principio de estos Colloquios, y en la que expresa lo siguiente:

Tornando a la persona de Erasmo digo que él es hombre muy sabio en todo género de letras divinas e humanas, es muy conocido e favorecido de todos los príncipes eclesiásticos e seglares de la cristiandad, a los cuales a ganado assí con la sinceridad de su vida e doctrina, como con la facilidad e dulçura de su lengua e pluma, en lo qual creo que es oy el más insigne hombre de nuestro tiempo, e aun de muchos de los passados (Ruiz de Virúes, 2005:10).

1) La obra de traducción de Ruiz de Virués

El motivo fundamental que lleva a Ruiz de Virués a traducir los Coloquios de Erasmo es el interés que le manifiestan personas con ideas renovadoras dentro de la Iglesia por conocer esta obra y que no lo pueden satisfacer por no tener acceso a la lengua latina, idioma en el que Erasmo la escribió, como todas sus obras. Los coloquios que integran la traducción de Virués son 11 , de los que los ocho primeros fueron traducción suya y seleccionados a instancias de personas interesadas en los mismos, razón por la que él no se planteó su publicación; los otros 3 coloquios tienen autoría traductora diferente, de la que solamente consta la del pronotario Lluys Mexía como traductor del coloquio noveno.

Ni la razón de la lengua en sí, ni la finalidad didáctica de la misma, fueron -por tanto-, los motivos principales que condujeron a Virués a la traducción. Sí, en cambio, fue la ocasión de mostrarnos su idea de la

\footnotetext{
${ }^{2}$ Texto de la Biblioteca de la Universidad de Valencia.
} 
traducción, sus habilidades para tal oficio y su conocimiento de la lengua, tanto latina como castellana.

En primer lugar, conviene señalar que para Virués la traducción no puede hacerse literalmente, sino que conlleva una cierta recreación de la obra que se está traduciendo. Por ello se permite la licencia de añadir, quitar y siempre con la intención de bien interpretar el pensamiento. Precisamente, en la introducción que Virués hace al Colloquio llamado Puerperio [l] y que titula Argumento del intérprete en el siguiente colloquio llamado Puerperio, Virués considera que este Colloquio debe ser traducido a todas las lenguas. En él nos ofrece su visión de la traducción y, concretamente, nos dice con qué criterios la ha realizado en esta obra:

\begin{abstract}
Por esso diré que no me parece que todos los Colloquios son para trasladar, pero éste sin falta es digno de ser pasado no en una lengua sino en todas, por la mucha gracia e doctrina natural e moral que contiene, a la qual yo añadí algunas cosas por dos respetos: el uno, por declarar más la intención de Erasmo, no poniendo sentencia mía sino aclarando la suya, y esto no me parece añadir sino interpretar; porque a mi juicio el oficio de buen intérprete es hazer que la obra, si ser pudiere, quede tan graciosa, clara y elegante en la lengua en que se saca como era en la lengua en que primero estava. Y esto no se puede hazer sino quitando e poniendo palabras, porque muchos vocablos, refranes e alusiones tienen gracia en una lengua que, si al pie de la letra se sacasen en otra, serían muy grandes desgracias.

El otro respeto por que, en este Colloquio y en otros, añadí fue por juntar con lo que Erasmo dize algo de lo que yo siento, lo qual no creo que hará la obra menos dina de leerse que sin ello sería, pero porque ay muy gran diferencia de la sabiduría e ingenio de Erasmo a mi grosería, todo lo desta segunda manera fuera añadido yrá señalado con dos manecitas, la una en principio la otra en la fin de lo añadido desta manera, assí en este Colloquio como en todos los otros" (Ruiz de Virúes, 2005:15-16).
\end{abstract}

En segundo lugar, Ruiz de Virués también aprovecha la introducción a este Colloquio [I] para recordarnos tres cosas: primera, la importancia que, siguiendo el ejemplo de Erasmo, concede a la educación. Esto explica que el Colloquio llamado Puerperio, dedicado a la educación infantil ocupe el primer lugar; segunda, que Erasmo escribió los coloquios, tanto para resaltar la importancia del aprendizaje de la lengua latina como para darnos doctrina, es decir, su visión de los problemas que importaban a los hombres de su tiempo; tercera, pese a la importancia que tiene la lengua latina, no debe olvidarse -nos dice Virués-, que también las lenguas romance o vernáculas la tienen. Una y otras lenguas tienen su público y, por tanto, su uso debe responder a las necesidades reales, de personas y de lugares: 
De aquí es que Erasmo, como para otras edades uviese dado doctrina en otros Colloquios, quísola dar en éste para el nacimiento e crianza de los niños y por esto entre los que yo aquí he trasladado me parece que éste debe ser el primero que se lea e después los otros. No todos los que Erasmo hizo, pues que él nos lo hizo todos para dar doctrina sino solamente para mostrar a hablar en latín las cosas que ordinariamente tratamos, hazemos, dezimos y traemos entre manos, y aun de los Colloquios hechos para enseñar; no me parece que se devrían sacar todos, porque cosas ay que están bien en latín para los latinos y no lo están en romance para el labrador e para la vejezuela que lo podrían leer u oir quando otro lo leyese.

Allende desto, como estos Colloquios por la mayor parte traten cosas usuales, es de mirar que, por la gran distancia de las tierras, cosas que se usan en Alemania no se usan en Castilla, como es en este Colloquio arreboçar el aldava de la puerta de la parida e, por esso allá pudieron tener gracia y sazón e acá fáltales todo (Ruiz de Virúes, 2005:15).

\section{CISNEROS Y NEBRIJA ANTE LA LABOR DE LA TRADUCCIÓN}

El Cardenal Cisneros quería y deseaba vivamente llevar a cabo en vida el proyecto de la Políglota sin escatimar cuantos recursos económicos y personales fuesen necesarios. Objetivo que consiguió, ya que apenas terminada la impresión de la misma le sobrevino la muerte. Pero también le importaba el que la obra tuviera calidad, tanto desde el punto de vista teológico como filológico. A tal fin buscó los mejores expertos del momento en las lenguas originales en las que se habían escrito los textos sagrados y formó con ellos un equipo de estrechos colaboradores que él lideró, asumiendo la responsabilidad de que el trabajo se realizara en las mejores condiciones. Las múltiples e importantes ocupaciones del Cardenal no le llevaron a desentenderse de dicha tarea, sino que al contrario, le hizo un seguimiento muy de cerca.

Cisneros era plenamente consciente del deterioro que habían sufrido los textos sagrados a través de las diferentes versiones que a lo largo del tiempo se produjeron, en hebreo, griego y latín. Por ello, era necesaria una reconducción de la situación que permitiera, por un lado, mejorar la calidad filológica de los textos a través del trabajo de buenos expertos en este campo y, por otra, reavivar los estudios bíblicos como base fundamental de la Teología. Al respecto, es muy esclarecedor el análisis que hace Walter Starkie:

En el prefacio de la Políglota, Cisneros consigna claramente los objetos que él y sus colaboradores pretendían al llevar a cabo su trabajo. Dice allí que ninguna traducción puede reflejar completa y 
exactamente el sentido del original, al menos en la lengua que Nuestro Señor hablaba. Y que los manuscritos latinos diferían tanto uno de otro que no podía menos de sospecharse que por la ignorancia y la negligencia de los copistas se habían hecho algunas alteraciones. Por eso era necesario, como ya deseaban San Jerónimo y San Agustín, acudir a los originales de las Sagradas Escrituras, corrigiendo los libros del Antiguo Testamento con arreglo a su texto hebreo, y los del Nuevo Testamento con arreglo al texto griego. Era preciso que todos los teólogos pudieran beber aquel agua de vida eterna en su propia fuente. Esta es la razón por la cual Cisneros había ordenado la impresión en la lengua original y en sus traducciones, recurriendo, para llevar a cabo la tarea, a la ayuda de los más hábiles filólogos, y buscando los más antiguos manuscritos hebreos y griegos. Así revivirían los decaídos estudios sobre las Sagradas Escrituras. (Starkie 1943:392-393).

Pero Cisneros dará un paso aún más allá, fijando un criterio fundamental a seguir para la revisión y la corrección de los textos sagrados: acudir a las fuentes originales de los mismos, estén en hebreo, griego o latín, y desde éstas hacer las correcciones en las lenguas correspondientes. Respetar al máximo, por tanto, los textos originales y evitar hacer correcciones en una lengua original desde las otras lenguas originales. Este criterio general constituirá para el Cardenal una regla básica y de la que ningún colaborador podrá apartarse. Ello supondrá, según Cisneros, que el Antiguo Testamento habrá que corregirlo desde los mejores originales hebreos, así como el Nuevo Testamento con los más fiables textos originales en griego. En el caso de la Vulgata de San Jerónimo, de la que circulaban diversas versiones manuscritas e impresas, se la revisa también siguiendo el mismo criterio anterior, y para ello se utilizan los textos latinos de mejor garantía, sin tener en cuenta los textos originales en hebreo y griego. En definitiva, la labor de depuración y fijación que la propuesta o criterio de Cisneros generaba, se la llamaba en la Universidad de Alcalá "correctorio» del Cardenal y tenía como objetivo:

La intangibilidad de los textos originales, a los que se proponía acomodarse lo máximo posible, y se distanciaba del intento de reconstrucción académica de los textos que pretendían los humanistas. (García Oro, 1992:493).

El criterio de Cisneros sobre cómo corregir los textos, pero respetando los originales, no fue asumido, al menos, por parte de Nebrija, quien debido a su forma de ser produjo entre el equipo de expertos que Cisneros había reunido un enfrentamiento pasajero que le hizo abandonar la tarea que el 
Cardenal le había encomendado en la Políglota y le condujo de nuevo a su cátedra de Salamanca, tal como nos lo recuerda el siguiente pasaje:

Tuvo Cisneros un incidente con Nebrija, hombre brusco de carácter y poco dúctil para imponer modificaciones a su criterio. Pensaba Nebrija se trataba de corregir los originales, no de fijar los textos; con tal idea redactó sus trabajos, hasta que Cisneros le salió al paso; la cosa molestó a Nebrija, que abandonó la colaboración y marchó en los primeros meses de 1505 a regentar su cátedra de Gramática en Salamanca. (García Mercadal, 1939:109-110).

Gracias a la mediación del obispo de Ávila, Don Francisco Ruiz, Nebrija le explica al Cardenal los motivos que le llevan al desacuerdo, y lo que -en última instancia-, provocará el abandono de la tarea que le había sido encomendada:

Yo tenía deliberado de no entender mas en la emendacion de la Biblia

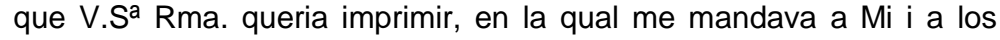
otros Hebreos, i Griegos, que entendiessemos Yo en el latin, i los otros cada uno en su lengua. I preguntome V.S. que porque no queria entender en ello? Yo le respondi, que porque cuando vine de Salamanca, Yo dege alli publicado que venia a Alcala para entender en la emendacion del Latin, que esta comúnmente corrompido en todas las Biblias latinas cotejandolo con el Hebraïco, Caldaïco i Griego. I que agora, si alguna cosa falta en ello, se hallase que todos cargarian a mi la culpa, i dirian, que aquella ignorancia era mia, pes que dava tan mala cuenta del cargo, que me era mandado. Entonces V.S ${ }^{\text {a }}$ me dijo, que hiciesse aquello mesmo, que a los otros avia mandado, que no se hiciesse mudanza alguna de lo que comúnmente se halla en los Libros antiguos: mas que si sobre ello a mi otra cosa pareciesse, que devia escribir algo para fundamento, i prueva de mi intencion. A esto yo dige, que si algo yo escribiese, de mi rebusco Yo hinchiria mucho mayor bodega, que todos los otros de su vendimia principal... De manera, que desde entonces hasta agora Yo no cure mas de la impresión, ni por mandado de V.S ${ }^{\mathbf{a}}$ me fue dicho, que entendiesse en ella... (Sáenz-Badillos, 1996:145).

Es evidente, que entre Cisneros y Nebrija hubo un desacuerdo en relación a los criterios a seguir en la traducción de la Políglota: mientras que para el primero, Cisneros, solo los textos originales de cada lengua debían ser los que debían tenerse en cuenta en la corrección de los textos, para el segundo, Nebrija, todos los textos originales de no importa qué lengua debían considerarse en cualquier corrección textual, sobre todo y principalmente, en el caso de la Vulgata. 


\section{JUAN LUIS VIVES Y EL ARTE DE TRADUCIR E INTERPRETAR}

Juan Luis Vives conoce muy bien y, además, las tiene en cuenta, las dos tradiciones anteriores y más significativas que en torno a la traducción se produjeron, y que se derivaron del trabajo de versión de obras clásicas escritas en griego al latín. Ambas tradiciones están representadas fundamentalmente por Cicerón y San Jerónimo.

Cicerón, por su parte, representando la tradición del clasicismo latino desprecia la traducción literal y el seguimiento pedestre del texto literal. El clásico latino entiende la traducción como un ejercicio de elocuencia, lo que le lleva a identificar lo esencial del texto original para posteriormente recrearlo en el idioma propio. Por tanto, la filosofía que orienta la labor traductora en Cicerón es la de trabajar la versión con sentido libre, nada de esclavitud ante el texto original (cf. Calvo, 1984:70-71).

San Jerónimo, por otra parte, representando la tradición cristiana y autor de la versión Vulgata de la Biblia, se constituye en un referente teórico principal en el campo de la traducción a lo largo de toda la Edad Media y llega su influencia hasta la época moderna. La aportación de San Jerónimo va más allá de la de Cicerón, ya que éste generaliza el sentido de la traducción para todo tipo de textos, mientras que aquél diferencia el sentido de la traducción según de qué texto se trate. De aquí que el Santo distinga dos tipos de traducción: traducción libre para los textos profanos, al igual que Cicerón que lo hace con carácter general, y traducción literal para los textos sagrados, no confundiendo ésta con cualquier traducción pedestre o esclava de la letra. Ello, en su opinión, obligará al traductor a conocer muy bien la propia lengua para poder hacer la versión en las mejores condiciones (cf. Calvo, 1984:71-72).

De todas formas, seguro que Vives también conoce otras aportaciones al campo de la traducción que se han producido desde la Baja Edad Media hasta los primeros años del Renacimiento por la vía de la traducción de textos sagrados al romance o por la versión de textos clásicos, principalmente del griego a la lengua latina ${ }^{3}$.

\footnotetext{
${ }^{3}$ Entre las contribuciones más significativas de este periodo, cercano a Juan Luis Vives, tenemos las que representan eruditos de la traducción como el griego Chrysoloras (13551415), el italiano Guarino de Verona (1370-1460) y el también italiano Leonardo Bruni (13701444), quien al traducir textos de Platón, Jenofonte, Plutarco y Aristóteles lo hace con una bella factura, siguiendo las tradiciones de Cicerón y Petrarca y proclamando que una buena traducción debe hacerse bajo aquellos requerimientos que aseguren la calidad de la misma.
} 
3.1. Aportaciones específicas de Juan Luis Vives en el campo de la traducción e interpretación

En términos generales, Vives entiende la traducción como el ejercicio de versión de las palabras de una lengua a otra, pero manteniendo y conservando el sentido del texto original (cf. Vives, 1948:803-Tomo II).

Pero a partir de aquí, y en esto va a consistir su aportación específica, incorpora la contribución de carácter textual que al respecto hizo San Jerónimo, pero yendo más lejos o ampliando dicho carácter; es decir, tiene en cuenta como cuestión previa el tipo de texto de que se trata y a partir de aquí procede a la traducción. Vives, a diferencia de la distinción jeronimiana entre textos profanos (traducción libre) y sagrados (traducción fiel), distingue tres tipos de textos a los que corresponden también tres tipos distintos de traducción:

En algunas de estas versiones se atiende no más que al sentido; en otras, la sola frase y la dicción, como si alguien intentare trasladar a otras lenguas las oraciones de Demóstenes o de Marco Tulio o los poemas de Homero o Virgilio Marón, observando con escrupulosa fidelidad la fisonomía y el color de estos grandes autores [...] El tercer género es cuando la sustancia y las palabras mantienen su equilibrio y equivalencia, es decir, cuando las palabras añaden fuerza y gracia al sentido y ello cada una de por sí o unidas o en todo el cuerpo de la composición. (Vives, 1948:803-Tomo II).

Teniendo en cuenta el texto anterior de Vives, podemos expresar de la siguiente manera la relación que éste establece entre tipos de texto y traducción:

El primer tipo de texto sería aquel que antepone el qué: la esencia, al cómo: la forma. En este caso, lo importante es conservar el sentido y, por tanto, se puede traducir con cierta libertad, añadiendo las palabras o expresiones que puedan ayudar a comprender lo que se dice en el original. Parece que Vives está pensando en textos de carácter informativo (cf. Calvo, 1984:74).

En el segundo tipo de texto, lo que prevalece es la forma, el cómo. Para este caso, la traducción debe ser principalmente formal, atendiendo al cómo se dice, y afectaría básicamente a los textos sagrados, concretamente, a la Sagrada Escritura.

En el tercer tipo de texto, Vives conjuga los dos tipos de texto anteriores, es decir, el sentido y la forma, y a tal fin se deberá combinar, a la vez, la conservación del contenido y de aquellas expresiones y formas idiomáticas de la lengua original en la lengua traducida, salvo cuando la traslación literal no sea posible y haya que traducir por equivalencia. Este tercer método de traducción que Vives propone, exige un equilibrio entre el 
sentido y la forma, y plantea más dificultades y esfuerzo para el traductor. Parece ser que Vives está pensando en este tercer tipo de texto en textos literarios, tal como indica Calvo:

\begin{abstract}
También aquí, aunque sin expresarlo claramente, creemos que Vives se está refiriendo a la traducción de textos literarios que exigirían por lo menos una analogía con el original. La imposibilidad de llegar a este compromiso parece clara para el humanista, otorgando con ello una mayor libertad a la traducción poética en lo que a la forma se refiere, pero exigiendo, a su vez, que se guarde la mayor fidelidad posible a los contenidos semánticos de la "sententiae summa» (Calvo, 1984:74).
\end{abstract}

Aparte la aportación de Vives en relación a la tipología textual, también hay otras cuestiones que le preocupan al valenciano en el oficio de la traducción:

También aquí, aunque sin expresarlo claramente, creemos que Vives se está refiriendo a la traducción de textos literarios que exigirían por lo menos una analogía con el original. La imposibilidad de llegar a este compromiso parece clara para el humanista, otorgando con ello una mayor libertad a la traducción poética en lo que a la forma se refiere, pero exigiendo, a su vez, que se guarde la mayor fidelidad posible a los contenidos semánticos de la «sententiae summa». (Calvo, 1984:74).

-La cualificación del traductor en las lenguas que traduce y en la materia objeto de traducción. Si éste no está versado en ambos campos, difícilmente se pueden esperar buenos resultados, tal como nos lo recuerda en el siguiente pasaje:

Para una traducción honrada es de necesidad imprescindible que el intérprete conozca a fondo los recursos y la energía de una y otra lengua; con todo, conviene que esté más ejercitado en aquélla a la cual traduce. No pueden traducirse en toda su integridad aquellas palabras cuyo sentido se ignore. Con menguada equivalencia traducirá las obras de Aristóteles quien no fuere filósofo, ni los libros de Galeno quien no fuere médico. (Vives, 1948:586-Tomo II).

-Dar importancia a las traducciones. Vives pone de manifiesto el interés que tiene para todas las disciplinas utilizar el instrumento de la traducción, lógicamente si éste se usa bien:

Las interpretaciones no solamente convienen, sino que son de primera necesidad, así para todas las disciplinas y las artes todas, sino para 
todas las circunstancias de la vida, siempre que sean fieles. Son falsas bien por desconocimiento de las lenguas o de la materia de que se trata. (Vives, 1948:804-Tomo II).

- La calidad de la versión realizada. Vives exige perfección, exactitud y calidad en el trabajo de traducción y es bastante crítico con las versiones mal hechas:

Con cuanto mayor exactitud hubieres conservado la gracia de la dicción y con cuanto mayor propiedad la hubieres interpretado, tanto mejor y más excelente será la versión que con mayor verdad sea expresión de su originalidad, como lo es el pequeño libro ciceroniano De la universalidad, que es una parte del Timeo platónico, y que yo propongo a todos los estudiosos como modelo de traducción irreprochable. (Vives, 1948:806-Tomo II).

En conclusión, Juan Luis Vives en el campo de la traducción e interpretación aporta su contribución a la tradición teórica traductológica que recibe, especialmente por su tipología textual, y sabe situarse en lo que será el futuro de este campo, gracias a la concepción moderna que del Humanismo tiene y al rigor científico con el que trabaja:

Si bien Vives parte en líneas generales de la concepción ciceroniana/jeronimiana hasta aquel momento tradicional y vigente, supera a ambos en su relatividad del hecho traductor como supeditado a la tipología textual, adoptando, no una «forma» abstracta y universalmente válida para toda traducción que no sean las Sagradas Escrituras, sino toda una serie de posibilidades de traducción, un abanico esencialmente trilítero, que nos llegará a nuestros días y que planteará con siglos de antelación, no solo las principales premisas textuales del Romanticismo, sino la misma traductología germánica de base textual que se está dando en esta segunda mitad del siglo $\mathrm{XX}$. (Calvo, 1984:74-75).

\section{LA OBRA TRADUCTORA DE VALDÉS}

La formación académica que recibió Juan de Valdés en Alcalá le preparó para llevar a cabo en su día tareas de traducción. El conocimiento lingüístico que obtuvo del latín, griego y hebreo le capacitaba para que más tarde y, por motivos estrictamente religiosos, dedicara una parte de su tiempo a la labor de traducción. También con esta actividad Valdés continúa la tradición humanista, y se suma a la lista de humanistas reformadores que igualmente acometieron este trabajo. 
Valdés limita sus traducciones a textos estrictamente sagrados, llevado por sus inquietudes religiosas y también como forma de comunicación con el grupo que animaba religiosamente durante su estancia en Nápoles. Dos son las traducciones que se conservan de Valdés: una parte del Evangelio de San Mateo, traducido del griego, y todo el Salterio, vertido del hebreo.

Bien que las traducciones no ocupen un espacio relevante en su actividad profesional, no obstante en el trabajo dedicado a este campo, Valdés nos transmite suficientemente su pensamiento en relación a este oficio y que se puede expresar en los enunciados siguientes:

1) La labor de traducción debe intentar mejorar aquellos textos, ya previamente vertidos, pero que no consiguieron la calidad traductora necesaria. Este es el criterio que Valdés sigue a la hora de traducir un texto u otro, al elegir -en su caso- por ejemplo, el Salterio en lugar de las Epístolas de San Pablo, tal como le explica dicha decisión a su amiga Giulia Gonzaga en la dedicatoria-prólogo del mismo:

[...] porque entiendo que los Salmos tienen más necesidad de buena traslación que las Epístolas, por estar ellos en los libros latinos más impropiamente trasladados (sic) que no están ellas. (Ricart, 1964:135).

2) La traducción, según Valdés, debe respetar al máximo el texto original, especialmente cuando se trata de textos sagrados a los que hay que tener mucho respeto. Ello le lleva a Valdés, tal como indica en la dedicatoriaprólogo, a forzar la lengua castellana, con tal de preservar el sentido del texto original:

[...] os los he puesto (los salmos de David) en romance castellano, sacándolos de la letra hebrea, casy palabra por palabra, en quanto lo ha sufrido el hablar castellano. $Y$ aun me he atrevido más vezes a la lengua castellana, hablando impropiamente, que a la hebrea, alterándola. Esto he hecho assy, pareciéndome cosa conueniente y justa que las cosas escrittas con Espíritu Santto sean tratadas con mucho respeto. He mezclado del mío algunas palabras a fin que la letra lleue más lustre, vaya más clara y más sabrosa. Estas, porque sean conocidas, van escrittas con tinta colorada, pretendiendo que se les ha de dar el crédito que se deue dar a palabras de hombre haziendo diferencia entre ellas y las que son de Spíritu Santo... (Ricart, 1964:135).

El artilugio que utiliza Valdés de las diferentes tintas es todo un símbolo interpretativo de su opinión en relación al cómo debe hacerse la traducción. Al respecto tiene interés el siguiente pasaje: 
Claro es que la distancia del Espíritu al hombre es abismal; de ninguna manera pueden confundirse, aunque interfieran. Pero no significa, en absoluto la anulación del hombre: las palabras en tinta roja llaman la atención sobre el lustre, la claridad, lo sabroso, términos que podrían acercarse al que se repite tanto en el Diálogo de la lengua, el primor importantísimo para Valdés. Por tanto, conviene tener siempre presente la experiencia del traductor, el trabajo de continua confrontación de dos o más códigos expresivos, asiduo ejercicio mental que seguramente se intensificó en la estancia italiana, en la cual es probable que llegase al bilingüismo. La reflexión sobre la lengua fue cultivada a lo largo de toda su vida, incrementándose acaso en Italia; el cuidado en la elaboración de sus escritos siempre tuvo que preocuparle. (Barbolani, 2006:46).

3) La traducción, según Valdés, es un oficio nada fácil, por la natural dificultad que presenta la diversidad de vocablos de las lenguas en juego, la de origen y la de llegada, es decir, la lengua original y la lengua en que se vierte el texto en cuestión. Nadie mejor que Valdés para referirnos dicha dificultad:

MARCIO Confiesso que tenéis razón. Pero si avéis romançado alguna cosa latina o italiana, bien creo avréis también hallado otros muchos vocablos, aliende de los que avéis dicho, que os an puesto en aprieto, quiriendo esprimir enteramente en castellano lo que significan en latín o italiano.

VALDÉS Y aun porque cada lengua tiene sus vocablos propios y sus propias maneras de dezir, ay tanta dificultad en el traduzir bien de una lengua en otra, lo qual yo no atribuigo a falta de la lengua en que se traduze, sino a la abundancia de aquélla que se traduze, y assí unas cosas se dizen en una lengua bien que en otra no se pueden dezir assí bien, y en la mesma otra ay otras que se digan dizen mejor que en ninguna. (Valdés, 1997:235).

4) Finalmente, Valdés piensa -al igual que todos los humanistas reformadores que abordaron la cuestión de la traducción-, que es una temeridad practicar la traducción sin un conocimiento adecuado de las lenguas objeto de la traducción. En el no buen dominio de una de las dos lenguas en juego, está la fuente de todos los errores que potencialmente se pueden producir en el proceso de verter de una lengua a otra:

CORIOLANO Esso stá muy bien dicho y es assí en la verdad.

VALDÉS Por esto es grande la temeridad de los que se ponen a traduzir de una lengua en otra sin ser muy diestros en la una y en la otra.

MARCIO Desta manera pocas cosas se traduzirían. 
VALDÉS Assí avría más personas que supiessen las lenguas necesarias, como son la latina, la griega y la hebrea, en las quales está escrito todo quanto bueno ay que pertenezca assí a religión como a ciencia. (Valdés, 1997:235-326).

\section{LA OBRA TRADUCTORA DE FRAY LUIS DE LEÓN}

Fray Luis acomete en su vida una importante obra de traducción. Ello se explica por el amor y la atracción personal que la lingüística le despertó, más que por su dedicación profesional al campo de la filología que no la tuvo, ya que la Teología y la Sagrada Escritura fueron sus dos actividades centrales. Sin embargo, esto no significa que su labor en este ámbito no haya sido realmente relevante; al contrario, sí lo ha sido, por la calidad de la misma (cf. Álvarez, 1990:241). Esta calidad, según algunos reconocen, fue posible por las dotes extraordinarias que el agustino poseía para este menester y por el buen conocimiento que tenía de la literatura antigua y de las lenguas clásicas, griego y latín, así como del hebreo (cf. Cuevas, 2001:28).

Precisamente, la combinación en el sabio salmantino de las dotes que poseía para la traducción y el interés por relacionar esta actividad con el campo de la hermenéutica, la explicación, le condujo a una constante búsqueda de lo divino y lo humano o de lo divino en lo humano, y explica, en definitiva, la importancia que tuvo este quehacer en su trabajo teológico y escriturístico por excelencia:

La traducción era más que una faceta de su «creación literaria». Tenía una finalidad sagrada, como no lo tenía para otros humanistas del XVI. Como traductor Fray Luis se enfrentó con las dualidades centrales de su vida: el conflicto entre el espíritu y la letra; entre lo figurado y lo literal; entre lo hebraico y lo cristiano; entre lo divino y la encarnación de lo divino en el lenguaje. Para él, como para San Agustín, el fenómeno lingüístico era análogo a la encarnación: antes de hacerse hombre, Dios se «vistió» del lenguaje humano. La vida de Fray Luis fue un esfuerzo constante por comprender cómo lo divino se significa en lo humano (Maurer, 1996:441).

Fray Luis lleva a cabo la actividad de traducción principalmente en romance, tanto en su obra poética como en la escrita en prosa, guiándole siempre en la selección de los textos a traducir la calidad de los mismos. La obra poética que el agustino tradujo fue relativamente abundante ${ }^{4}$.

\footnotetext{
${ }^{4}$ Entre ella conviene reseñar la traducción de las Églogas de Virgilio y de los dos primeros libros de sus Geórgicas; unas veinticinco Odas de Horacio; poemas sueltos de Tibulo y Ausonio, la Olímpica primera, de Píndaro, y la Andrómaca, de Eurípides. De la Sagrada
} 
En cuanto a la labor traductora en prosa de Fray Luis, la Exposición de El Cantar de los Cantares de Salomón es su obra cumbre, que tradujo del hebreo y la vertió en lengua romance castellana (1561 y 1562), justamente cuando el sabio salmantino se encontraba en la juventud madura, al tener alrededor de treinta y tres años. Esta edad ya le permitía al agustino, por una parte, mostrar su gran saber, pero, por otra, le empujaba a tener comportamientos impulsivos en la defensa de lo que creía, que conllevaba riesgos en la época que le tocó vivir, tal como realmente le sucedió:

Alrededor de los treinta y tres años, en su juventud radiante, cuajada de saber y de impetuosidad generosa, andaba el poeta agustiniano cuando emprendió la versión directa del hebreo, con su exposición en lengua romance, del Cantar de los Cantares, el libro más glosado, y quizá más difícil de glosar, de la Sagrada Escritura. Esto acontecía entre los años 1561 y 1562. Por entonces, Fr. Luis ha salido ya triunfante en las difíciles pruebas a que se ha sometido su saber y su ingenio. Su temperamento, noble e impetuoso, le impulsa a lo arduo, a romper rutinas y acomodaciones. No le gusta el saber a medias. Ahonda con originalidad en los problemas teológicos y escriturarios. Trae una visión nueva y anchurosa a la vida universitaria. Y una capacidad de estudio excepcional. Posee perfectamente el griego, el hebreo y el latín. Y es un enamorado cultivador del idioma vernáculo. Más tarde habrá de ser su más elocuente y exaltado panegirista. (García, 1991, Vol. I:51).

Esta obra ha tenido y tiene singular relevancia desde el punto de vista de la traducción. Los criterios y los elementos de traducción que se ponen de manifiesto en este manuscrito, consideramos que son extrapolables al conjunto de toda la obra que el agustino tradujo, salvando, como es lógico, matices particulares condicionados por cada obra. Por esta razón, el examen general de cómo Fray Luis entiende la traducción, se va a extender a toda su obra, aunque nos apoyemos directamente en el manuscrito Exposición de El Cantar de los Cantares de Salomón 5 .

En la decisión de Fray Luis de traducir y exponer dicha obra, aparte de satisfacer la demanda de Isabel Osorio, influyó también el interés del

Escritura, Fray Luis tradujo del hebreo buen número de Salmos; el capítulo último del libro de los Proverbios, capítulos VI y VII del Libro de Job (Cf. Cuevas, 1997:32-33).

${ }^{5}$ El motivo que le llevó al agustino a llevar a cabo esta obra fue la demanda personal que recibió de Isabel Osorio, monja del convento de Sancti-Spiritus de Salamanca, para que le tradujera al castellano el Cantar de los Cantares y le explicara también el sentido alegórico del texto, aspecto tan importante en el mismo. Ante tal demanda, Fray Luis respondió positivamente, aun sabiendo los riesgos que corría por el hecho de verter al romance castellano el libro sagrado, ya que dicha práctica era perseguida por la Inquisición. 
agustino por acometer la tarea nueva de verter del hebreo un texto realmente complejo, cuestión que le suponía un reto:

\begin{abstract}
A este primer propósito se agregaba el gusto que el poeta experimentaba en la versión de aquel divino epitalamio, como ejercicio de su ingenio y de su arte en el conocimiento de la lengua hebrea [...] De tiempo atrás le atraía el texto enigmático del maravilloso Cantar. Era éste su primer empeño exegético, su primera versión del hebreo y su primer torneo prosístico en lengua romance. Su espíritu superior se crecía ante las dificultades de la empresa. (García, 1991, Vol. I:52).
\end{abstract}

Fray Luis, cuando acometió la traducción del Cantar, ya había leído el manuscrito que sobre la misma obra había realizado el religioso y poeta Arias Montano, buen amigo suyo, con el título Exposición sobre el Cantar de los Cantares de Salomón. La cesión del manuscrito que éste le hace al agustino fue con el compromiso de que se lo vertiera al latín, cosa que no hizo de inmediato. Respecto a la posible influencia del manuscrito en el de Fray Luis, en opinión de los críticos, es difícil saberlo.

Una vez terminada la traducción y explicación de la obra, el salmantino era consciente de dos riesgos que existían al respecto. El primero, la dificultad que conllevaba su lectura y la interpretación del sentido del texto relacionado con la temática del amor; el segundo riesgo, la posibilidad de que el manuscrito se extendiera, pese al carácter estrictamente personal que tenía, ya que la destinataria en exclusiva era Isabel Osorio. Ambos riesgos se materializaron.

Ante el riesgo de la no adecuada interpretación del contenido del texto, el agustino lo previene suficientemente en el Prólogo de su manuscrito:

Pues entre las demás Escrituras divinas, una es la canción suavísima que Salomón, rey y profeta, compuso, en la cual, debajo de un enamorado razonamiento entre dos, pastor y pastora, más que en alguna otra Escritura, se muestra Dios herido de nuestros amores con todas aquellas pasiones y sentimientos, que este afecto suele y puede hacer en los corazones más blandos y más tiernos [...] A cuya causa la lección de este Libro es dificultosa a todos y peligrosa a los mancebos, y a todos los que aún no están muy adelantados y muy firmes en la virtud; porque en ninguna Escritura se explica la pasión del amor con más fuerza y sentido que en ésta. Del peligro no hay que tratar; la dificultad, que es mucha, trabajaré yo de quitar cuanto alcanzaren mis fuerzas, que son bien pequeñas. (Luis de León, 1991, Vol. I:71-72). 
El segundo riesgo fácilmente se materializó también, pese a que el agustino tomó todas las medidas que a él le correspondían para que el manuscrito no se difundiera. Sin embargo, el enemigo o el curioso lo tenía dentro del convento o más bien, dentro de la habitación, fr. Diego de León. Éste era quien le arreglaba la habitación y esto le permitió robar el manuscrito, leerlo y facilitar su distribución al resto de religiosos del convento, también fuera del convento salmantino, e incluso, más allá de la Universidad de Salamanca.

Lógicamente, la reacción que produjo el manuscrito, como era de esperar, fue grande, y se convirtió en el caldo de cultivo para que once años después de su versión y difusión, Fray Luis fuera encausado y sufriera penas de cárcel. En este largo periodo crecieron los detractores, quienes lo acusaban de no tener razón, pero también aumentaron los defensores para quienes el agustino "se adelantó a su tiempo, tanto en su apreciación de la Vulgata como en la sabia versión del Cantar, con sus comentarios sagacísimos, en los que introducía no pocas rectificaciones" (cf. García, 1991, Vol. I:55). A esta defensa, cinco años después de que Fray Luis abandonara la cárcel, se sumaron también los suyos, religiosos del convento de San Agustín de Salamanca y amigos, con el objetivo de restaurar el buen trabajo realizado y dignificar sus cualidades como teólogo, escriturista y filólogo. Sus superiores, a fin de cancelar las críticas derivadas de la interpretación luisiana del Cantar y para que se conociera bien su pensamiento real, le ordenaron que vertiera el manuscrito al latín; cosa que hizo con el título In Canticum Canticorum Explanatio, y "en la que declara y razona de nuevo su literalidad, $y$, a la vez, agrega dos exposiciones del sentido místico y espiritual" (cf. García, 1991, Vol. I:55).

A continuación se examina lo que Luis de León entiende por traducción (objeto), el método que utiliza y lo que se puede decir que ha sido la contribución del agustino al campo de la traducción.

\subsection{Fray Luis y el concepto de traducción}

Aunque resulte difícil condensar en breves palabras lo que para Fray Luis significa la traducción, ésta, en su opinión, debe conseguir ser básicamente fiel a los textos y ser vertida a lengua vulgar permitiendo accesibilidad a los mismos y que, al mismo tiempo, posea riqueza lingüística. Nada mejor que la siguiente cita del propio agustino, tomada de su Prólogo a la Exposición de El Cantar de los Cantares, y que nos sirve para entender su concepto general de la traducción:

Lo que yo hago en esto son dos cosas: la una es volver en nuestra lengua palabra por palabra el texto de este Libro; en la segunda, declaro con brevedad no cada palabra por sí, sino los pasos donde se ofrece alguna oscuridad en la letra, a fin que quede claro su sentido 
así en la corteza y sobrehaz, poniendo al principio el capítulo todo entero, y después de él su declaración. Acerca de lo primero procuré conformarme cuanto pude con el original hebreo, cotejando juntamente todas las traducciones griegas y latinas, que de él hay, que son muchas, y pretendí que respondiese esta interpretación con el original, no sólo en las sentencias y palabras, sino aun en el concierto y aire de ellas, imitando sus figuras y maneras de hablar cuanto es posible a nuestra lengua, que, a la verdad, responde con la hebrea en muchas cosas [...] El que traslada ha de ser fiel y cabal y, si fuere posible, contar las palabras para dar otras tantas, y no más ni menos, de la misma cualidad y condición y variedad de significaciones que las originales tienen, sin limitarlas a su propio sentido y parecer, para que los que leyeren la traducción puedan entender toda la variedad de sentidos a que da ocasión el original, si se leyese, y queden libres para escoger de ellos el que mejor les pareciere. El extenderse diciendo, y el declarar copiosamente la razón que se entiende, y el guardar la sentencia que más agrada, jugar con las palabras añadiendo y quitando a nuestra voluntad, eso quédese para el que declara, cuyo propio oficio es; y nosotros usamos de él después de puesto cada un capítulo en la declaración que se sigue. Bien es verdad que, trasladando el texto, no pudimos tan puntualmente ir con el original; y la cualidad de la sentencia y propiedad de nuestra lengua nos forzó a que añadiésemos algunas palabrillas, que sin ellas quedara oscurísimo el sentido; pero éstas son pocas, y las que son van encerradas entre dos rayas de esta manera [ ]. (Luis de León, 1991, Vol. I:74-75).

Vemos, pues, en este texto luisiano, que los criterios fundamentales que han orientado su labor traductora han sido, por un lado, la fidelidad al texto original, pero cotejándolo con versiones en otras lenguas. La fidelidad al texto, sin embargo, no es para el agustino una esclavitud sino que, al contrario, deja margen de libertad para añadir las palabras necesarias que den al texto sentido y claridad:

Se ha hablado de la obsesión de Fray Luis por la fidelidad al texto bíblico en su traducción, algo que él mismo había advertido. Ello es cierto, pero conviene tener en cuenta que tal fidelidad no le lleva, al menos en el caso de las traducciones en verso, a la sequedaz y rigidez. (Ramajo, 2006:LXXVI).

Por otro lado, también le importa llevar a cabo la traslación del texto a la lengua vulgar, teniendo en cuenta las figuras y maneras de hablar del texto original, siempre que éstas no impidan la claridad del texto vertido a la lengua vulgar. 
Concretamente, esto es lo que Fray Luis hace en su traducción del Cantar de los Cantares siguiendo los criterios mencionados: lo traslada fielmente a lengua vulgar, pero modificando algunos párrafos de la Vulgata, como resultado de una mejor interpretación de los mismos a la luz de los correspondientes términos hebreos:

Es decir, que en principio no intentó rebasar su propósito de filólogo, de exegeta gramatical; quiere penetrar bien y precisar el valor de las palabras, sorprender sus matices y fijar su acepción más adecuada y lógica, según el contexto y los distintos significados del término hebreo, con el fin de interpretar más adecuadamente el sentido profundo de los pasajes que resultaban de más abstrusa y difícil interpretación. Es la suya una labor de arqueólogo del lenguaje, de intérprete sabio que no olvida que, para poder penetrar con paso seguro en la explicación mística de aquellos versículos misteriosos, es imprescindible conocer y valuar primero la contextura formal de las palabras, que son el receptáculo del espíritu. (García, 1991, Vol. I:56).

\subsection{El método de Fray Luis en la traducción}

La idea que el agustino tiene sobre la traducción la va a materializar siguiendo el método de la aplicación del sentido literal y, sobre todo, cuando se trata de los Libros Sagrados. Ahora bien, para el salmantino, este procedimiento debe realizarse mediante el examen del texto original, en la lengua en que esté:

Lo que hago es [...] volver en nuestra lengua palabra por palabra el texto de este Libro (Cantar de los Cantares) [...] Procuré conformarme cuanto pude con el original hebreo, cotejando juntamente todas las traducciones griegas y latinas que de él hay, que son muchas, y pretendí que respondiese esta interpretación con el original, no solo en las sentencias y palabras, sino aun en el concierto y aire de ellas, imitando sus figuras y maneras de hablar cuando es posible a nuestra lengua, que, a la verdad, responde con la hebrea en muchas cosas. (Luis de León, 1991, Vol. I:74).

El método de recurrir al texto original para la versión que, en opinión de Fray Luis, daba consistencia a la traducción, chocaba con las prácticas más generalizadas en esta materia que no acudían a los textos originales cuando se trataba, sobre todo, de los Libros Sagrados, tomándose como referencia única el texto bíblico de la Vulgata. Lógicamente, el hecho de que el agustino tradujera el Cantar de los Cantares, teniendo en cuenta también el correspondiente texto original hebreo, a fin de hacer la mejor versión posible en lengua vulgar, le produjo sinsabores físicos y espirituales. 
Fray Luis considera que el método del sentido literal en la labor de traducción es un buen camino para dar cuenta del texto en origen y en destino. Esta tarea la conceptúa el salmantino como la corteza de la letra, en el sentido de que ofrece una primera lectura material del texto (filológica), que es absolutamente necesaria para poder hacer otras lecturas, a partir de ésta, que afecten a cualquier aspecto del contenido. En relación a su trabajo realizado en el Cantar de los Cantares, así describe dicha tarea:

\begin{abstract}
Solamente trabajé en declarar la corteza de la letra, así llanamente, como si en este Libro no hubiera otro mayor secreto del que muestran aquellas palabras desnudas $y$, al parecer dichas y respondidas entre Salomón y su Esposa, que será solamente declarar el sonido de ellas, y aquello en que está la fuerza de la comparación y del requiebro; que, aunque es trabajo de menos quilates que el primero, no por eso carece de grandes dificultades. (Luis de León, 1991, Vol. I:72).
\end{abstract}

Ciertamente, el agustino es plenamente consciente de que más allá de la literalidad hay otros sentidos y que deben, además, ser puestos de manifiesto y por las personas doctas en ello, tal como añade el salmantino a continuación, y referido a la misma obra:

Cosa cierta y sabida es que en estos Cantares, como en persona de Salomón y de su esposa, la hija del rey de Egipto, debajo de amorosos requiebros, explica el Espíritu Santo la Encarnación de Cristo y el entrañable amor que siempre tuvo a su Iglesia, con otros misterios de gran secreto y de gran peso. En este sentido espiritual no tengo que tocar, que de él hay escritos grandes libros por personas santísimas y muy doctas que, ricas del mismo Espíritu que habló en este Libro, entendieron gran parte de su secreto, y como lo entendieron lo pusieron en sus escrituras, que están llenas de espíritu y de regalo. Así que en esta parte no hay que decir, o porque ya está dicho, o porque es negocio prolijo y de grande espacio. (Luis de León, 1991, Vol. I:72).

En suma, la tarea de la traducción literal, aplicada al Libro de los Cantares no pretende ignorar la necesidad de conocer ese sentido espiritual del ágape (otro sentido distinto al literal). No lo afronta, tal como el agustino ha referido anteriormente, porque "hay escritos grandes libros por personas santísimas y muy doctas" y porque añadir algo más sería "negocio prolijo y de grande espacio". Por tanto, Fray Luis considera que debe limitarse -ya que es también muy importante-, a "declarar la corteza de la letra" (cf. García de la Concha, 2004:204-205).

Los criterios metodológicos seguidos no solo están expresados en el Libro de los Cantares; igualmente Fray Luis los indica en su versión en 
prosa de la Exposición del Libro de $J o b^{6}$, en la Dedicatoria que hace $A$ la muy religiosa madre Ana de Jesús, carmelita descalza:

Verdad es que el estilo poético y la mucha antigüedad de la lengua y del libro le hacen muy oscuro en no pocos lugares. Mas esta oscuridad vencerá con sus oraciones V.R., que obligada es a favorecerme con ellas, pues pone este peso en mis hombros. En que hago tres cosas: una, traslado el texto del libro por sus palabras, conservando, cuanto es posible, en ellas el sentido latino y el aire hebreo, que tiene su cierta majestad; otra, declaro en cada capítulo más extendidamente lo que se dice; la tercera, póngale en verso, imitando muchos y antiguos que en otros libros sagrados lo hicieron y pretendiendo por esta manera aficionar algunos al conocimiento de la Sagrada Escritura, en que mucha parte de nuestro bien consiste, a lo que yo juzgo. (Luis de León, 1991, Vol. II:28).

Fray Luis expresa, pues, de forma clara una de las tres tareas que se fija en esta obra: que la traducción, aun manteniendo el sentido literal, debe conservar también el sentido latino y el aire hebreo. De este modo, una vez más, se refuerza el método de traducción que se considera el más idóneo: lograr el sentido literal en la lengua vulgar, pero teniendo en cuenta el texto originario, sea hebreo, griego o latino. El agustino, es plenamente consciente que también con esta obra, el Libro de Job, está también contribuyendo al desarrollo de la lengua vulgar, a través de la actividad traductora:

El ejercicio de la traducción resultaba, pues, imprescindible para el dominio perfecto de los matices de la lengua. Así se concebía como un excelente ejercicio no sólo entre estudiantes sino entre eximios profesores.

El valor lingüístico de la traducción era algo evidente para ellos y una forma insuperable de cuidar, por un lado, la latinidad y por otro la lengua vulgar. (Álvarez, 1990:254).

Por ello, se puede afirmar que en ambas obras, el Cantar de los Cantares y el Libro de Job, el agustino hizo un gran esfuerzo en la tarea de la traducción, poniendo en juego variedad de recursos lingüísticos que, en definitiva, no han hecho sino que enriquecer la lengua vulgar:

\footnotetext{
${ }^{6}$ De esta obra se conserva una versión en prosa (Biblioteca de la Universidad de Salamanca) y otra versión en forma poética (Academia de la Historia). Esto llevó -en opinión del P. Féliz García-, a que varios expertos en la obra de Fray Luis como el P. Herrera, Nicolás Antonio y Mayans y Siscar no mencionaran la versión en prosa (Cf. García, 1991,Vol. II:20-21).
} 
En pleno ardor juvenil emprendió el comentario y estudio de los dos libros sagrados que ofrecen más problemas y dificultades: del Cantar de los Cantares y del Libro de Job. Su propósito primero fue en ambos declarar el sentido textual e ilustrar con toda suerte de recursos etimológicos, históricos, étnicos y geográficos los pasajes que a nuestro modo de comprender de hoy -es decir, de su tiempo, que es el nuestro también- resultan extraños, difíciles y sorprendentes. (García, 1991, Vol. Il:5).

Pero, el despliegue de recursos lingüísticos que Fray Luis desarrolla en el ejercicio de la traducción no lo hace de forma indiscriminada; al contrario, lo que busca en definitiva es que las palabras que se usen correspondan realmente a las cosas, para elaborar un texto accesible en lengua vulgar, en este caso, castellana:

Por eso huye en las traducciones de arreglos a gusto del intérprete. $Y$ quiere en ellas, no palabras pegadizas, sino aquellas que hablen en castellano "como nacidas en él y naturales» [...] Conformidad de las palabras y las cosas. Nada más alejado de cualquier modo de nominalismo, o de un oficio de filólogo pendiente exclusivamente de la letra. Fray Luis quiere palabras que vengan, en cuanto al fondo, "como nacidas» a las cosas, y que en cuanto a la forma consuenen «como metrificadas». (Álvarez, 1956:21).

\subsection{Fray Luis y su contribución a la traducción}

Así, pues, la contribución del salmantino al campo de la traducción se puede resumir en las siguientes aportaciones:

a) Parece que la aportación más novedosa del agustino a la teoría de la traducción consistió en haber intentado reproducir, no sólo el significado de los textos bíblicos, sino también el significante lingüístico en toda su complejidad, a través de fonemas, número y colocación de sílabas, ritmos, cualidad de palabras, estructuras de oraciones y cláusulas, etc. (cf. Cuevas, 2001:32-33 y Bell, 1927:269).

b) Su relación con el lenguaje por medio de la traducción fue la de un maestro. Por ejemplo, al traducir y comentar el Cantar de los Cantares dejó constancia de que no pretendía solamente la exactitud en la interpretación de las palabras del original, sino su ritmo y música (cf. Durán, 2000:195).

c) La convergencia en el salmantino del descubrimiento de la lengua vulgar romance para tratar convenientemente asuntos elevados con su gran conocimiento del hebreo bíblico y de la tradición clásica grecorromana, ha hecho que Fray Luis sea considerado como gran traductor $y$, probablemente, primer gran teórico de la traducción (cf. Peñalver, 1997:4647 y Pozuelo y Aradra, 2000:221). 
d) Finalmente, Fray Luis puso de manifiesto con su obra de traducción ser un humanista auténtico, al haberse ocupado del estudio de las lenguas y literaturas griega y latina. A esta formación se incorpora, para el idioma personal, el modo de seleccionar «las palabras, las imágenes literarias, la estructura y el ritmo de la frase», en cuanto son transferibles, a otro idioma (cf. Ortega, 2002:17).

\section{REFERENCIAS BIBLIOGRÁFICAS}

ÁLVAREZ, Lucio: La gramática española del siglo XVI y Fray Luis de León. Madrid: Junta de Comunidades de Castilla la Mancha, 1990.

ÁLVAREZ, Saturnino: "Sobre Fray Luis de León filólogo". Separata de La Ciudad de Dios, Vol. CLXIX, Imprenta del Real Monasterio de El Escorial, 1956, pp. 3-27.

BARBOLANI, Cristina: "Introducción". En: Juan de Valdés, Diálogo de la lengua. Madrid: Ediciones Cátedra, 2006, pp. 11-102.

BATAILLON, Marcel: Erasmo y España. México: Fondo de Cultura Económica, 1986.

BELL, Aubrey F. G.: Luis de León. Un estudio del Renacimiento Español. Barcelona: Editorial Araluce, 1927.

CALVO, Juan José: "Juan Luis Vives: ¿Un pionero de la traductología moderna? Apuntes sobre una discrepancia". En: Quaderns de Filología, Miscelànea Sanchis Guarner. Universitat de Valencia, Vol. 2, 1984, pp. 69-78.

CUEVAS, Cristobal: "Introducción". En: Fray Luis de León, De los nombres de Cristo. Madrid: Ediciones Cátedra, 1997, pp. 13-123. , "Introducción". En: Fray Luis de León, Poesías completas. Madrid: Editorial Castalia, 2001, pp. 7-53.

DURÁN, María Ángeles: Si Aristóteles levantara la cabeza. Madrid: Ediciones Cátedra, 2000.

ERASMO DE ROTTERDAM: Coloquios familiares. Edición de Alonso Ruiz de Virúes (Siglo XVI). Barcelona: Editorial Anthropos, 2005.

GADAMER, Hans-Georg: Verdad y método (Trad. de Ana Agud Aparicio y Rafael de Agapito). Salamanca: Ediciones Sígueme, 2005.

GARCÍA DE LA CONCHA, Víctor: Al aire de su vuelo. Estudios sobre santa Teresa, Fray Luis de León, san Juan de la Cruz y Calderón de la Barca. Barcelona: Galaxia Gutenberg, 2004.

GARCíA, Félix: "Introducciones y notas". En: Fray Luis de León, Obras completas castellanas, Vol. I y II. Madrid: Biblioteca de Autores Cristianos (B.A.C.), 1991, pp. 51-69.

GARCíA MERCADAL, José: Cisneros (1436-1517). Zaragoza: Editorial. Luz. 1939. 
GARCía ORO, José: El Cardenal Cisneros. Vida y empresas. Volumen II. Madrid: Biblioteca de Autores Cristianos (B.A.C.), 1992.

LUIS DE LEÓN: Obras completas castellanas, Vol. I y II. Prólogos y notas de Félix García. Madrid: Biblioteca de Autores Cristianos (B.A.C.), 1991.

MAURER, Christopher: "La 'figura' en Fray Luis: poesía y traducción". En: Víctor García de la Concha y Javier San José (Eds.), Fray Luis de León, Historia, Humanismo y Letras. Salamanca: Ediciones Universidad de Salamanca, 1996, pp. 441-450.

ORTEGA, Alfonso: Fray Luis de León, humanista. Salamanca: Editorial CEIAS, 2002.

PEÑALVER, Patricio: La mística española (siglos XVI y XVII). Madrid: Akal Ediciones, 1997.

PÉREZ DE CHINCHÓN, Bernardo: La lengua de Erasmo nuevamente romançada por muy elegante estilo. Edición de Dorothy S. Severin. Madrid: Anejo XXXI del Boletín de la Real Academia Española, 1975.

POZUELO, José María y Rosa María ARADRA: Teoría del canon y literatura española. Madrid: Ediciones Cátedra, 2000.

RAMAJO, Antonio: "Edición, Prólogo y Notas". En: Fray Luis de León, Poesía. Barcelona: Galaxia Gutenberg, 2006, pp. XXI-CXXXIII.

RICART, Domingo: "Transcripción, introducción y notas". En: Juan de Valdés, Diálogo de Doctrina Christiana y el Salterio traducido del hebreo en romance castellano. México: Universidad Nacional Autónoma de México, 1964.

RUIZ DE VIRÚES, Alonso: "Argumento del Intérprete en el siguiente Colloquio llamado Puerperio". En: Erasmo de Roterdam, Coloquios familiares, edición de Alonso Ruiz de Virúes (Siglo XVI). Barcelona: Editorial Anthropos, 2005, pp. 15-16.

SÁENZ-BADILLOS, Ángel: "La Biblia Políglota Complutense". En: Luis. Jiménez Moreno (Coord.), La Universidad Complutense Cisneriana. Madrid: Editorial Complutense, 1996, pp. 137-153

SEVERIN DOROTHY S.: "Introducción". En: Bernardo Pérez de Chinchón, La lengua de Erasmo nuevamente romançada por muy elegante estilo, editada en 1533. Texto de la Biblioteca de la Universidad de Valencia. Madrid: Anejo XXXI del Boletín de la Real Academia Española, 1975, VII-XXXII.

STARKIE, Walter: La España de Cisneros. Barcelona: Editorial Juventud, 1943.

VALDÉS, Juan de: "Diálogo de la lengua". En: Obras Completas, I. Diálogos, Escritos espirituales. Cartas. Madrid: Ediciones de la Fundación José Antonio de Castro, 1997, pp. 153-266.

VILLACAÑAS, José Luis: ¿Qué imperio? Córdoba: Editorial Almuzara, 2008.

VIVES, Juan Luis: Obras Completas. Tomos I y II. Madrid: Editorial Aguilar, 1947-1948. 